\title{
The Effects of Nitrogen Fertilization on Water Use by Crested Wheatgrass
}

\author{
R.J. WILLIAMS, K. BROERSMA AND A.L. VAN RYSWYK
}

\begin{abstract}
The application of $\mathbf{N}$ fertilizer to crested wheatgrass on a dry rangeland site increased yields substantially. In the early part of the growing season when moisture was not limiting, soil moisture was withdrawn from the fertilized site at a higher rate than from the unfertilized plots. At later periods in the growing season the soil water potential curves paralleled each other with the fertilized crop growing under conditions of lower soil water potential. The decreased soil water potential was confirmed when the actual evapotranspiration, as measured by the energy balance method, was examined. The data indicate that for a period following rapid growth in the spring, the evapotranspiration of the fertilized block was less than that of the unfertilized. The soil water potential data indicate that seasonal evapotranspiration was slightly higher on the fertilized plot than on the unfertilized. The water use efficiency, in terms of biomass produced per unit of water used, was much greater for fertilized crested wheatgrass and resulted in increased yields.
\end{abstract}

The need for improved forage yields within the dry Interior grassland regions of British Columbia has been recognized for many years. In 1974 an intensive project examining the effects of nitrogen $(\mathrm{N})$ fertilization on rangeland seeded with crested wheatgrass (Agropyron desertorum[Fisch.] Schutt.) was begun. As an integral part of this study, micrometeorological data on evaportranspiration were collected. The purpose of these data was to observe differences in how water was used by fertilized and unfertilized rangeland.

The benefits of nitrogen fertilizer on seeded and natural rangeland have been discussed by numerous authors. Sneva et al. (1968) found higher yields, increased seed heads, and more rapid maturity on fertilized crested wheatgrass range. Studies on the effects of fertilizer on the water use characteristics of rangeland grasses are controversial because not all were made in the same way. Some measure the amount, others the rate of water use. Smika et al. (1965) found that seasonal water use by nonirrigated fertilized native range was not significantly different from that of unfertilized range. Similarly, Lauenroth and Sims (1976) noted that in Great Plains grasslands, $N$ fertilization did not increase the amount of seasonal soil water used but it

The senior author is meteorologist, B.C. Ministry of the Environment, Resource Analysis Branch Kamloops, British Columbia, V2B 8A9; Broersma and van Ryswyk are forage agronomist and pedologist, Research Station, Agriculture Canada, Kamloops, British Columbia.

The technical assistance of Dr. R.G. Wilson, Dr. T.A. Black, Mr. D. Evans, and Mr. P.J. Smith is gratefully acknowledged.

The research is a cooperative investigation of the B.C. Min. Environ., Resource Analysis Branch, and Agriculture Canada, Res. Sta., Kamloops (Agr. Can., Kamloops, Contribution No. 272).

Manuscript received February 20, 1978. may affect the rate of water use. In addition, Sneva et al. (1958) observed that water use for fertilized crested wheatgrass was increased over unfertilized at early stages of development.

Viets (1962) recognized that fertilizer treatments increased water use efficiency (ie. the ratio of dry matter yield to water evapotranspired) of crops grown under dryland conditions. Similar results were observed by Bleak and Keller (1974) while studying fertilized crested wheatgrass. These authors estimated actual evapotranspiration $(E)$ by the water balance method using measurements of soil moisture and precipitation.

The need for accurate measurements of $E$ to explain the effects of fertilization on rangeland is evident from the work of Wight and Black (1972). These authors suggest that "water-as an immediate requirement for plant growth-does not limit production on rangeland ecosystems to the extent that nutrient availability does."' Consequently, the purpose of the present paper is to accurately measurc differences in the actual evapotranspiration and water use efficiency over a growing period, from adjacent fertilized and unfertilized crested wheatgrass test sites.

\section{Materials and Methods}

The experimental site was on an Orthic Black Chernozem soil (Canada Soil Survey Committee, Sub-Committee on Soil Classification 1978) at an elevation of $1,000 \mathrm{~m}$ approximately $13 \mathrm{~km}$ south of Kamloops. This soil is believed to be equivalent to a Typic Haploboroll (U.S. Dep. Agr. 1975) with the following selected characteristics; $15 \mathrm{~cm}$ loam over $35 \mathrm{~cm}$ gravelly clay loam over compact gravelly clay loam glacial till; $2.3 \% \mathrm{C}$ in top $15 \mathrm{~cm}$; available water capacity $(-0.3$ to -15 bars percentage for $0-50 \mathrm{~cm}$ depth range $10 \mathrm{~cm}$ water, for $0-100 \mathrm{~cm}$ depth range $18 \mathrm{~cm}$ water. The data used in this study were collected during the summers of 1974 and 1975. The crop investigated was crested wheatgrass-an extremely drought-tolerant species. The study area had been seeded about 16 years earlier and the stand was well established and in excellent condition. In the spring of 1974 the plot with an area of 12 ha was divided, and a 3.2-ha block was fertilized with $150 \mathrm{~kg} / \mathrm{ha}$ elemental nitrogen applied as ammonium sulphate-urea.

Soil moisture data were determined graviemetrically, and soil water potentials were measured using a Wescor HR-33T Dewpoint mcrovoltmeter and PT 51-10 thermocouple psychrometers. These soil data were collected concurrently at depths of $2.5,10,20$, and $50 \mathrm{~cm}$. Yields were measured by clipping all plant material in $1 \mathrm{~m}^{2}$ at $5 \mathrm{~cm}$ above ground, oven drying, and wcighing. The soil and yield data were obtained at three replicated locations, within each of the fertilized and unfertilized blocks, and averaged. These data were collected over the growing season approximately every 10 days. 
Actual evapotranspiration was obtained using the energy balance approach shown in (1).

$\mathrm{R}_{\mathrm{N}}=\lambda \mathrm{E}+\mathrm{H}+\mathrm{G}$. . . (1)

where $R_{N}=$ net radiation flux

$\lambda E=$ latent heat flux

$\lambda=$ latent heat of vaporization

$\mathrm{E}=$ actual evapotranspiration

$\mathrm{H}=$ sensible heat flux, energy used in heating or cooling the air without any change of state taking place

$\mathrm{G}=$ soil heat flux

Equation (1) was transformed using the Bowen ration, $\beta$, of sensible heat flux $(H)$ to latent heat flux $(\lambda E)$.

$$
\beta=\frac{H}{\lambda E} \cdots
$$

Substitution of $\beta \lambda E$ for $H$ in (1) gives:

$$
\lambda E=\left(R_{N}-G\right) /(1+\beta) . . .
$$

Sargeant and Tanner (1967) showed that (2) could be solved in terms of the wet and dry bulb air temperature gradients $\Delta T_{W}$ and $\Delta T_{D}$ respectively, so that (2) becomes:

$$
\begin{aligned}
& \beta=\left[(S / \gamma+1)\left(\Delta T_{W} \Delta T_{D}\right)-1\right]^{-1} \ldots \ldots \text { (4) } \\
& \text { where } S=\text { slope of the saturation vapour pressure curve } \\
& Y=\text { psychrometic constant }
\end{aligned}
$$

In this study the temperature gradients were obtained using a psychrometric apparatus similar to that described by Black and McNaughton (1971), with a sensor separation of $0.5 \mathrm{~m}$. The lowest sensor was positioned approximately $0.5 \mathrm{~m}$ above the crop canopy. A complete description of the instrumentation is provided in Williams et al. (1978).

The actual evapotranspiration (E) data collection periods were June through August 1974 and July through August 1975. When weather allowed, the energy balance measurements were collected for a period of from 2 to 5 days on one test block (fertilized or unfertilized) and then immediately alternated for 2 to 5 days to the adjacent block. The energy balance equipment was operated for three such periods in 1974 and 2 in 1975. In both years long periods of inclement weather made operation of this electronic equipment impractical.

\section{Results and Discussion}

Figures $l a$ and $l b$ show a plot of $\lambda E /\left(R_{N}-G\right)$ vs $R_{N}$ for the unfertilized and fertilized test blocks, respectively. The term $\lambda E / R_{N}-G$ ) represents the proportion of the $R_{N}$ available at the surface which is used to support evapotranspiration. Wilson and Rouse (1972) have used the ratio of $\lambda E / R_{N}-G$ ) as an indirect measure of soil moisture stress. When this ratio is high, in excess of 0.84 , soil moisture is not limiting. In our research the ratio was found to be less than 0.84 on all occasions, indicating moisture stress. The slope of the regression line in Fig. l a shows that as $\mathrm{R}_{\mathrm{N}}$ increases, the proportion of energy used in evapotranspiration is reduced. This result indicates that although the unfertilized plants are extracting water from the soil at time of high evaporative demand, stomatal closure is occurring so that the increased demand cannot be maintained.

Data for the fertilized block (Fig. 1b) show that when $R_{N}$ values are low the energy used in evapotranspration is very low. Further, as $R_{N}$ increases the ratio of $\lambda E /\left(R_{N}-G\right)$ remains almost constant. These low values of the proportion of energy available for evapotranspration are indicative of a severely limited supply of soil moisture. (The circled data point was omitted from the regression as it was observed during heavy rain and was considered not representative.)

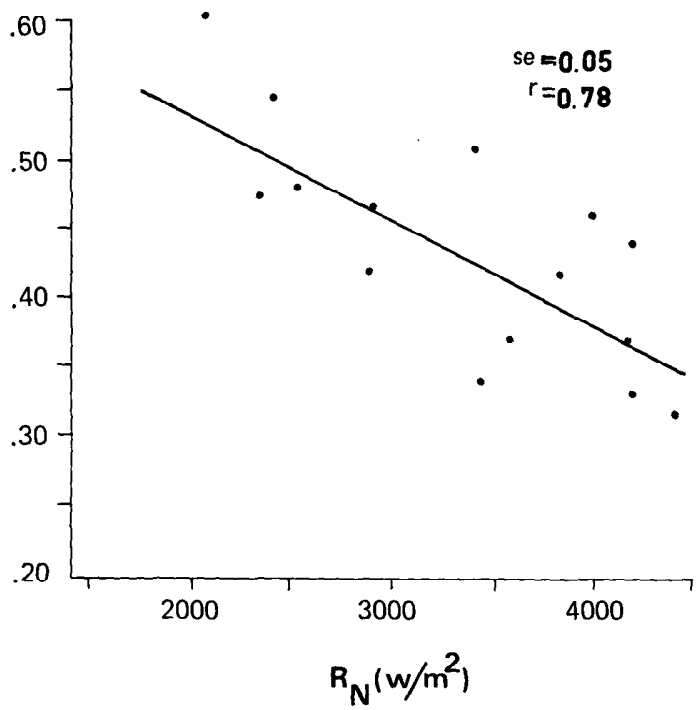

Fig. 1a. Ratio of energy used in evapotranspiration, $\lambda E /\left(R_{N}-G\right)$ vs net radiation $R_{N}$ (watts per square metre), unfertilized.

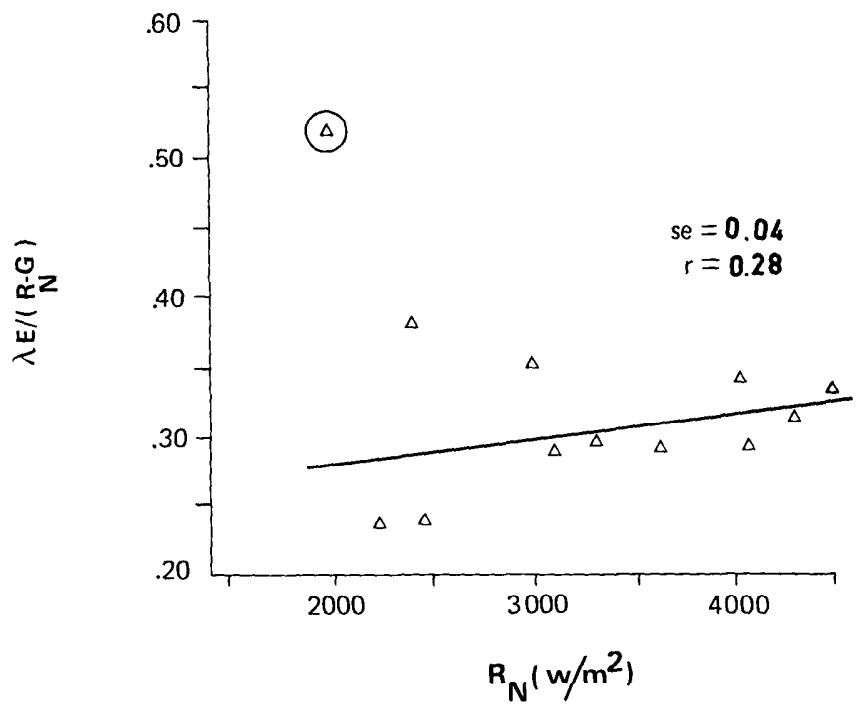

Fig. 1b. Ratio of energy used in evaportranspiration, $\lambda E /\left(R_{\left.N^{-G}\right)}\right.$ vs net radiation $R_{N}$ (watts per square metre) fertilized.

A comparison of Figures $l a$ and $l b$ indicates that in general a higher proportion of energy is used in evapotranspiration on the unfertilized block than on the fertilized in the period after rapid spring growth. The increased evapotranspiration of the unfertilized site is further evident in the August 1974 data (Fig. 2). The soil water potential data (Fig. 3) indicate that the fertilized crop was under more severe water stress than the unfertilized grass, a fact which is consistent with the lower rate of evapotranspiration over the fertilized plot at this time of the year. The yield data (Fig. 4), in contrast, indicate that the fertilized crested wheatgrass grows much more rapidly than the unfertilized early in the season, with the trend continuing to a lesser degree throughout the season. The soil water potential curves tend to verify this growth pattern. Rapid depletion of the fertilized plot's soil watcr occurred in the early part of the season when the soil was near field capacity. After this initial rapid extraction, the soil water potential curves for both plots parallel each other for the remainder of the season. At the end of the season, the fertilized plot has much lower soil water potential indicating that it is drier. This tends to verify the work of Black (1966) and Sneva et al. (1958), who noted that soil water was used more 


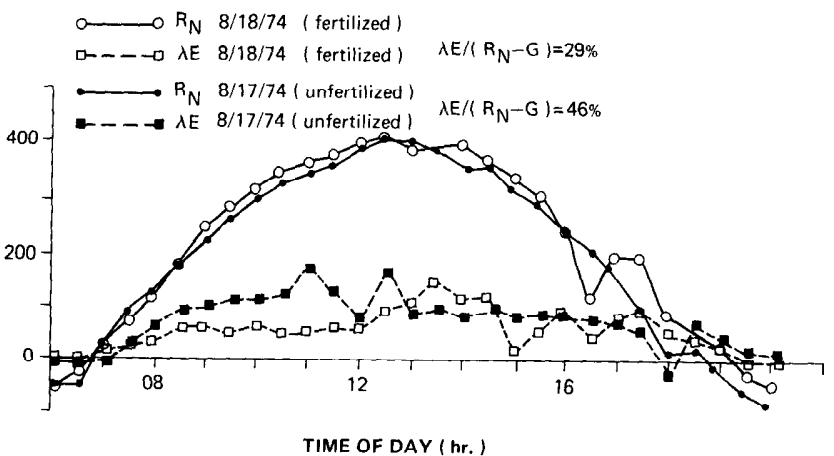

Fig. 2. Net radiation, $R_{N}$, and actual evapotranspiration $\lambda E$, expressed as energy fluxes (watts per square metre), on consecutive days over an unfertilized and fertilized test site.

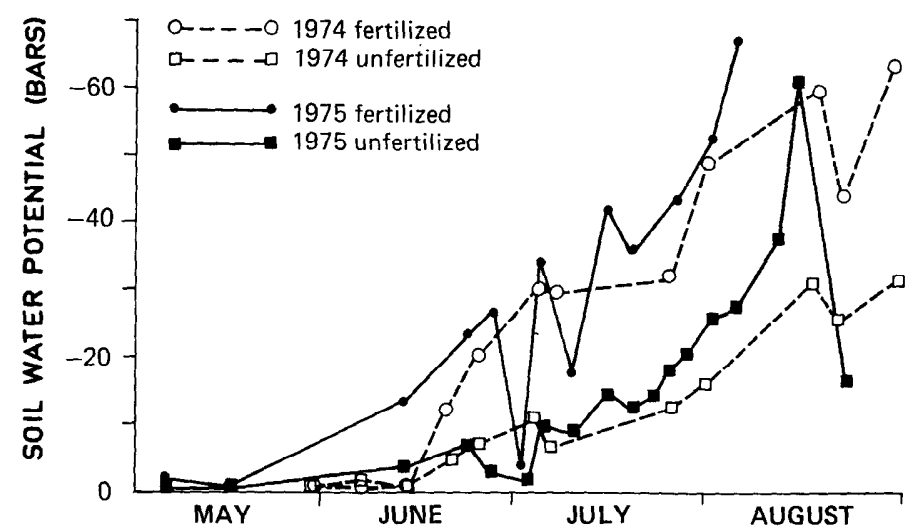

Fig. 3. Seasonal variation in soil water potential at $10 \mathrm{~cm}$.

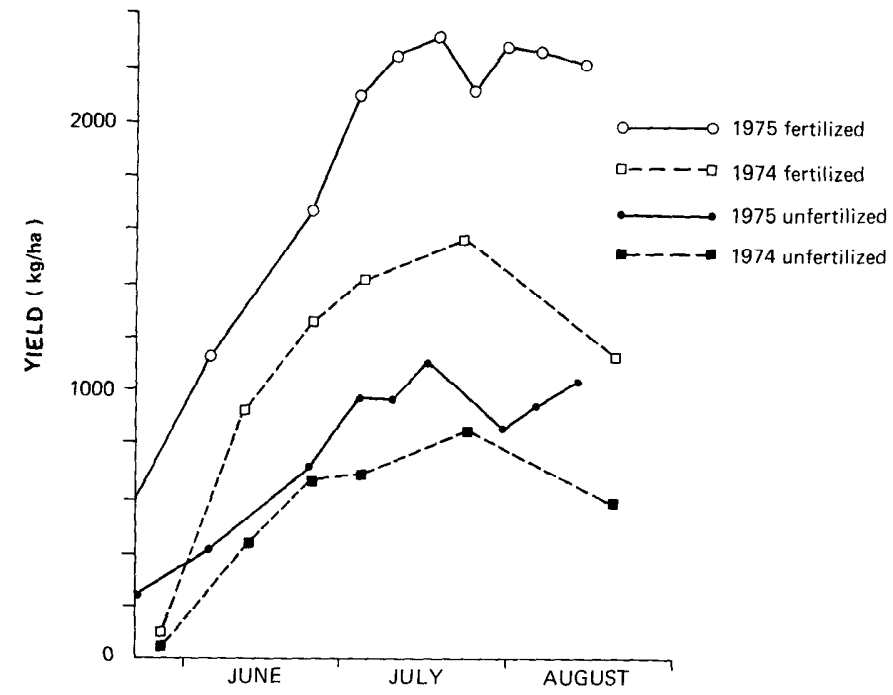

Fig. 4. Seasonal yield.

rapidly by fertilized grasses early in the season when water was not limiting.

Daubenmire (1972) noted that bluebunch wheatgrass (Agropyron spicatum) depleted the upper $20 \mathrm{~cm}$ of soil moisture by mid-May. Examination of our data indicates that the soil water potential decreased rapidly in May and early June. Unfortunately, energy balance data could not be collected during this critical period due to inclement weather and electronic difficulties.
The possibility that micrometeorological discrepancies between the two experimental blocks were responsible for the differences in evapotranspiration was examined. The gently sloping (U.S. Dep. Agr. 1951) terrain was slightly steeper on the fertilized block than on the unfertilized. This slope difference accounts for solar energy increase to the fertilized block during the growing season of less than 3\% (Frank and Lee 1966). Soil water potential data showed that spring soil water, though not at field capacity, was virtually identical at both sites (Fig. 3). Consequently, the disparity in water use efficiency is attributable to the fertilizer appliction, not to microsite influences. Also, the increased water use early in the season did not result in any water shortage for fertilized crested wheatgrass in the following spring. The total seasonal water use on both test blocks, based on percent soil moisture at the end of August, was virtually identical. For example, the soil moisture at $10 \mathrm{~cm}$ in late August 1974 was $9.7 \%$ and $7.5 \%$ on the unfertilized and fertilized test sites respectively. As is shown in Figure 3, this slight difference in soil moisture resulted in a large difference in soil water potential. Data for 1975 and unpublished data for 1976 and 1977 indicate that winter recharge was similar in the fertilized and unfertilized soils. These data confirm the belief of Wight and Black (1972) that native nutrient cycling appears inadequate to supply nutrients at rates needed to maintain potential production levels demanded by the climate. This demonstrates the importance of having adequate nutricnts at the beginning of the growing season when the rate of growth is high.

\section{Literature Cited}

Black, C.A. 1966. Crop yields in relation to water supply and soil fertility. p. 177-206. In: W.H. Pierce et al. (Ed.) Plant Environment and Efficient Water Use. Amer. Soc. of Agron. and Soil Sci. Soc. of Amer., Madison, Wisc.

Black, T.A., and K.G. McNaughton. 1971. Psychrometric apparatus for Bowen ratio determination over forests. Boundary-Layer Meteor. 2:246-254.

Bleak, A.T., and W. Keller. 1974. Crested wheatgrass yields as influenced by water conservation practices. Agron. J. 66:326-328.

Canada Soil Survey Committee, Subcommittee on Soil Classifications. 1978. The Canadian system of soil classification. Can. Dep. Agr. Pub. 1646. Supply and Services Canada, Ottawa, Ont. 164 p.

Daubenmire, R. 1972. Annual cycles of soil moisture and temperature as related to grass development in the steppe of Eastern Washington. Ecol. 53:417-424.

Frank, E.C., and R. Lee. 1966. Potential solar beam irradiation on slopes. U.S. Forest Serv. Res. Pap. RM-18, Fort Collins, Colorado. 116 p.

Lauenroth, W.K., and P.L. Sims. 1976. Evapotranspiration from a shortgrass prairie subjected to water and nitrogen treatment. Water Resource Res. 12:437-442.

Sargeant, D.H., and C.B. Tanner. 1967. A simple psychrometric apparatus for Bowen ratio determinations. J. Appl. Meteor. 6:414-418.

Smika, D.E., H.J. Haas, and J.F. Power. 1965. Effects of moisture and nitrogen fertilizer on growth and water use by native grass. Agron. J. 57:483486.

Sneva, F.A., D.N. Hyder, and C.S. Cooper. 1958. The influence of ammonium nitrate on the growth and yield of crested wheatgrass on the Oregon high desert. Agron. J. 50:40-44.

U.S. Department of Agriculture. 1975. Soil Taxonomy, A basic system of soil classification for making and interpreting soil surveys. U.S. Dep. Agr. Handbook No. 436, Washington, D.C. 754 pp.

U.S. Department of Agriculture. 1951. Soil Survey Manual. U.S. Dep. of Agric. Handbook No. 18, Washington, D.C. 503 pp.

Viets, F.G., Jr. 1962. Fertilizer and the efficient use of water. Advances in Agron. 14:223-264.

Wight, J.R., and A.L. Black. 1972. Energy fixation and precipitation use efficiency in a fertilized rangeland ecosystem of the northern Great Plains. $\mathbf{J}$. Range Manage. 25:376-380.

Wilson, R.G., and W.R. Rouse. 1972. Moisture and temperature limits of the equilibrium evapotranspiration model. J. Appl. Meteor. 11:436-442.

Williams, R.J., K. Broersma, and A.L. van Ryswyk. 1978. Equilibrium and actual evapotranspiration from very dry vegetated surface. J. Appl. Meteor. 17:1827-1832. 